
3 Research Square
Preprints are preliminary reports that have not undergone peer review.
They should not be considered conclusive, used to inform clinical practice,
or referenced by the media as validated information.

\title{
Nutritional Policies and Anaemia Among Under-five Children in Selected South Asian Countries: 1950-2016
}

\author{
Hanumant Waghmare ( $\square$ hanumantw@gmail.com ) \\ International Institute for Population Sciences \\ Nasim Ahamed Mondal \\ International Institute for Population Sciences
}

\section{Research}

Keywords: Nutritional Policies, Anemia, Nutritional Status, under-5 children, South Asia

Posted Date: October 18th, 2021

DOI: https://doi.org/10.21203/rs.3.rs-955225/v1

License: () (7) This work is licensed under a Creative Commons Attribution 4.0 International License. Read Full License 


\section{Abstract}

This study provides an understanding between the nutrition policies and nutritional status of under-5 children in South Asian countries. It gives an overview of nutrition policies and actions taken to improve the nutritional status of under-5 children in the South Asian context, focusing on Bangladesh, India, Nepal and Pakistan. The efforts were taken to understand the legislative actions and children's nutritional status in these countries and their past efforts to deal with anemia. To execute the efforts, data has been taken from the Global Health Observatory Data Repository (GHODR), Demographic Health Survey (DHS) and reviews some of the critical interventions in nutrition within the different countries and draws out several issues that bear on these policies' future evolution. The findings show Around 57.3 percent in India, 40 percent in Bangladesh, 43 percent in Nepal and 59 percent in Pakistan under-5 children were found anaemic in 2016. There are 33 percentage, 31 percent, 20 percent and 12 percent points reduction took place in 26 years between 1990 and 2016 in Bangladesh Nepal, India and Pakistan respectively. The low anemia prevalence was observed in Bangladesh and Nepal despite fewer policies and programs than in India and Pakistan which manifests quality of policy is more important rather than quantity of policy. The findings show that the growth of nutrition policies and the program has a slow pace but positively affects anemia among the under-5 children in South Asian countries. To eradicate anemia among the children and to achieve Sustainable Development Goals (SDGs), India and Pakistan need to take a policy lesson from the neighboring countries. This study suggests that National Nutrition Program requires inter-sectoral coordination between major Ministries within countries to get required level success within limited time.

\section{Background}

World Health Organisation (2020) defines Malnutrition, includes under nutrition, inadequate vitamins or minerals, overweight, obesity, and resulting diet-related non-communicable illnesses. The effects of poor nutrition begin in the womb, continue well into adulthood, and cycle across generations can be seen in figure 5 (Darnton-Hill et al., 2004). Malnutrition is the fundamental cause of morbidity and mortality among under-5 children (Sulaiman et al., 2018 ; Wagnew et al., 2018). Around $45 \%$ of mortality amongst children below five years of age are associated with under nutrition and these mainly occur in low- and middleincome nations (WHO, 2021). Despite multiple nutritional policies, anemia affects an estimated 165 million malnourished children under five years in low and middle income countries (Black et al., 2013). It is estimated globally that 30 percent of children under five are moderately or severely stunted, and 19 percent are moderately or severely underweight and almost 50 percent of all stunned children reside in Asia, 8 percent of children under five years of age are wasted worldwide, and two-thirds of all wasted children live in Asia (Unicef, 2018).

Malnutrition is the outcome of low food intake and is related somewhat to transmission factors such as crowding, water and environmental hygiene (Harriss, Gillespie, \& Pryer, 1990). The contributing factors in childhood malnutrition are low birth weight, inadequate breastfeeding and exclusive breastfeeding, inappropriate complementary feeding, maternal education, lack of proper nutrition, micronutrient intake, parity, birth spacing, household socioeconomic status, and food insecurity, poor sanitation, vaccination, and infectious diseases (Hoffman et al., 2017; Kismul et al., 2017; Tasnim, 2018).

The leaders from 159 countries in attendance at the 1992 International Conference on Nutrition in Rome declared their determination to eradicate hunger and decrease all forms of malnutrition. Soon after this, Industrialized and developing countries have started to formulate and implement food and nutrition-related policies (Mannan, 2003). With the economic development, nutrition policies have evolved to eradicate malnutrition among children (Amuna \& Zotor, 2008; Bishai \& Nalubola, 2002) but malnutrition rates have decreased slightly, and progress is very slow. The situation is worst in India, Pakistan, Bangladesh, and Nepal, which failed to reduce required level of malnourishment, even after a long history of nutritional policy commitment to combat anemia among children. Despite policies and social development, childhood malnutrition remains a significant public health and social challenge in less developed countries (Tasnim, 2018).

To address the contributing factors of malnutrition, South Asian countries adopted different policies and programs at different period. For every country, nutrition status constitutes the foundation for human development by reducing susceptibility to infections, disability, morbidity and mortality burden, enhancing cumulative lifelong learning capacities and adult efficiency (Demment et al., 2003). Nutrition is acknowledged as one of the most effective entry points for human development, poverty reduction and economic development, with high economic returns (Hunt \& John, 2005).

A large body of literature in four selected South Asian Countries have examined the trend, pattern, prevalence and the factors for the child anemia and nutrition in a broader context (Yusuf et al., 2019; Villalpando et al., 2003; Khan et al., 2016; Gebreweld et al., 2019; Singh and Patra, 2014; Bharati et al., 2015; Keokenchanh et al., 2021; Chowdhury et al., 2020). However, there is a lack of study for a comparative understanding between the nutrition policies and nutritional status of under- 5 aged children in South Asian countries. This study provides an overview of nutrition policies and actions taken to improve women's nutritional status in the South Asian context, focusing on Bangladesh, India, Nepal, and Pakistan.

The countries have a unique context; each of them is in different development stages in terms of nutrition policies and programs and have adopted varying approaches to strengthening their children's nutrition services. The countries provide a rich insight into what's being done to improve children nutrition status and what more needs to be done in future. Yet, for South Asia, children's nutrition is very much unfinished business, and, as the countries herself acknowledges, much more must be done to eradicate anemia. In this context, the present study aims to understand the comparative evolution of nutritional policies and programs in South Asian countries and their impact on children's nutritional status.

\section{Data And Methodology}

Data : The study collected year-wise anemia data from 1990 to 2016 from World Health Organization, Global Health Observatory Data Repository (World Health Statistics) for comparative analysis and latest round of Demographic Health Survey (DHS) data from four South Asian countries: India 2015-16 (NFHS4) $(\mathrm{N}=259,627)$, Nepal 2016 (NDHS-5) ( $\mathrm{N}=5,038)$, Pakistan 2012-13 (PDHS-3) ( $\mathrm{N}=12,708)$, and Bangladesh 2014 (BDHS-7) ( $=7,886)$ to study the distribution of children according to background characteristics in selected south Asian countries. DHS is considered a nationally representative sample as it covers

Page 2/11 
samples from across the country with a well-specified sampling procedure. All the DHS uses multi-stage stratified sampling for sample selection. Out of the four selected countries, India had the largest sample size, and Nepal had the smallest sample size. All the countries collected information on reproductive and child health, family planning, fertility, water and sanitation, nutrition, lifestyle, violence, and other topics using the prescribed format of the DHS's questionnaire with some country-specific modifications.

\section{Methods}

Bivariate analysis was used to study the distribution of children according to background characteristics in selected south Asian countries. To review the nutritional policies in selected south Asian countries, literature was collected from the various websites, journals and documents. Through the literature we investigated constitutional provision by various countries for the nutritional support. The selected countries have made efforts to improve the nutritional status through implementation of various programs and policies, thus we identified major policies and studied their nature, guideline and resolutions and chronological implantation by India, Pakistan, Nepal and Bangladesh. The identified polices and programme are plotted on graphs with prevalence of anemia.

Authors pooled (combination of selected countries data) the data of four south Asian countries to give an inkling of overall distribution of children according to background characteristics in south Asia. This study consider anemia for showing its historical changes over the period of time since authors could gather year-wise historical data of anemia only.

Independent variables: The selected socio-economic and demographic factors for the distribution under-five children in selected south Asian countries are: Child age in month (0-12, 13-24, 25-36, 37-48 and 49-60), Place of residence (Rural, Urban), Educational attainment of mother (No education, Primary, Secondary and Higher), Sex of the Household head (Male and Female), Source of drinking water (Piped water, Tubewell/borewell, Protected well, Unprotected well, River/dam/springs and Others), Type of fuel used for cooking (Clean, Wood, Crop residual, Animal dung and Others), Type of toilet Facilities (Flush toilet, Pit laterine, Open and Other), Wealth quintile (Poorest, Poorer, Middle, Richer and Richest).

\section{Results}

\subsection{Demographic profile the respondent}

Table 1 shows percentage distribution of children according to background characteristics in selected south Asian countries. In pooled data, there is an evenly distribution of percentage of children in each age group (approximately 20\%) except 49-60 month (19\%). In Bangladesh, below 12-month age group has the highest percentage of children (21\%) whereas 49-60 months age group has the lowest percentage (18\%) of children. In India, each age group has approximately the same percentage of children (about 20\%) except 49-60 months age group (21\%). Nepal has a minimum percentage of children in the 25-36 month age group whereas in Pakistan has the highest percentage of children in the below 0-12 month age group (21\%). 
Table 1

Percentage distribution of children according to background characteristics in selected south Asian countries

\begin{tabular}{|c|c|c|c|c|c|}
\hline Characteristics & Pooled & Bangladesh & India & Nepal & Pakistan \\
\hline \multicolumn{6}{|l|}{ Child age in month } \\
\hline 00-12 & 20.97 & 21.21 & 20.93 & 20.16 & 21.09 \\
\hline $13-24$ & 20.02 & 20.95 & 19.92 & 20.50 & 19.79 \\
\hline $25-36$ & 20.00 & 20.37 & 19.99 & 18.94 & 19.90 \\
\hline $37-48$ & 20.52 & 19.79 & 20.86 & 20.19 & 19.77 \\
\hline $49-60$ & 18.49 & 17.70 & 18.30 & 20.21 & 19.44 \\
\hline \multicolumn{6}{|l|}{ Place of residence } \\
\hline Urban & 28.97 & 25.41 & 28.05 & 53.96 & 31.93 \\
\hline Rural & 71.03 & 74.59 & 71.95 & 46.04 & 68.07 \\
\hline \multicolumn{6}{|c|}{ Educational attainment mother } \\
\hline No education & 32.38 & 16.41 & 30.06 & 34.25 & 49.35 \\
\hline Primary & 16.21 & 27.98 & 14.05 & 20.14 & 16.63 \\
\hline Secondary & 40.60 & 46.29 & 45.41 & 31.95 & 21.45 \\
\hline Higher & 10.81 & 9.32 & 10.48 & 13.66 & 12.57 \\
\hline \multicolumn{6}{|l|}{ Sex of household H } \\
\hline Male & 88.08 & 91.33 & 87.74 & 71.19 & 88.95 \\
\hline Female & 11.92 & 8.67 & 12.26 & 28.81 & 11.05 \\
\hline \multicolumn{6}{|c|}{ Source of drinking water } \\
\hline Piped water & 31.12 & 8.80 & 35.76 & 42.34 & 26.68 \\
\hline Tubewell/borewell & 51.02 & 79.60 & 45.16 & 41.84 & 55.91 \\
\hline Protected well & 2.11 & 0.18 & 2.55 & 0.62 & 1.82 \\
\hline Unprotected well & 3.32 & 0.45 & 4.44 & 1.03 & 1.30 \\
\hline River/dam/springs & 2.12 & 1.55 & 1.44 & 4.16 & 4.64 \\
\hline Others & 10.31 & 9.42 & 10.65 & 10.02 & 9.65 \\
\hline \multicolumn{6}{|c|}{ Type of fuel used for cooking } \\
\hline Clean & 31.99 & 14.67 & 32.10 & 23.11 & 42.25 \\
\hline Wood & 43.79 & 47.35 & 42.50 & 59.56 & 44.80 \\
\hline Crop residual & 7.82 & 21.81 & 6.97 & 2.84 & 3.27 \\
\hline Animal dung & 8.27 & 6.65 & 9.77 & 6.70 & 4.15 \\
\hline Others & 8.13 & 9.52 & 8.65 & 7.79 & 5.53 \\
\hline \multicolumn{6}{|c|}{ Type of toilet Facilities } \\
\hline Flush toilet & 46.43 & 16.13 & 42.33 & 62.56 & 76.36 \\
\hline Pit laterine & 13.24 & 68.53 & 6.53 & 8.49 & 5.53 \\
\hline Open & 33.12 & 2.74 & 44.10 & 19.95 & 13.51 \\
\hline Other & 7.21 & 12.59 & 7.04 & 9.23 & 4.60 \\
\hline \multicolumn{6}{|l|}{ Wealth quintile } \\
\hline Poorest & 24.48 & 22.71 & 25.36 & 21.39 & 22.70 \\
\hline Poorer & 21.27 & 19.15 & 21.98 & 21.19 & 20.05 \\
\hline Middle & 20.10 & 19.36 & 19.83 & 22.16 & 20.75 \\
\hline Richer & 18.54 & 19.81 & 18.12 & 20.48 & 19.06 \\
\hline
\end{tabular}




\begin{tabular}{|llllll|}
\hline Characteristics & Pooled & Bangladesh & India & Nepal & Pakistan \\
\hline Richest & 15.71 & 18.98 & 14.70 & 14.78 & 17.44 \\
\hline Total (N) & $100(285,259)$ & $100(7,886)$ & $100(259,627)$ & $100(5,038)$ & $100(12,708)$ \\
\hline \multicolumn{4}{|l}{ Source: Demographic and Health Survey: Bangladesh- } & 2014, India-2015-16, & Pakistan-2017-18, Nepal-2016 \\
\hline
\end{tabular}

If we look at the percentage distribution of children by residence, most of them live in rural areas (71\%). When it comes to country-wise distribution, Bangladesh, India, and Pakistan show the same trend except for Nepal. In Nepal, 54 percent of children live in an urban area. In the mother's education, 32 percent are illiterate, whereas 16 percent reported primary education, 40 percent of mothers said they have secondary education, and 11 percent reported higher qualifications. Approximately 46 percent of mothers from Bangladesh and India had a secondary level qualification. Remarkably, almost 50 percent of mothers in Pakistan have reported no education.

Most of the families have male head (88\%). More than 90 percent reported male head of the household in Bangladesh, followed by India (88\%), Pakistan (89\%), and Nepal (71\%) respectively. More than 50 percent of families have tube well/bore well as a drinking water source. Thirty-one percent of families are using piped water as drinking water. In Bangladesh, 80 percent of families use tube well/ bore well as a drinking water source. In India, Tube well/ bore well (45\%) and Piped water (36 \%) are the primary sources of drinking water. Four to five percent of Nepal and Pakistan families use River/ Dam/ Spring water as drinking water. At the same time, 4 percent of India's families are consuming drinking water from unprotected well.

Wood is the first choice as a cooking fuel in all the counties. Overall, 44 percent of families are using wood fuel for cooking. Crop residual is used as cooking fuel in Bangladesh (22\%). About 60 percent of families from Nepal are using wood as cooking fuel. About 46 percent of families use flush toilet facilities when it comes to toilet facilities, whereas 33 percent use Open defecation. Most families are using flush toilet facilities except Bangladesh families (only $16 \%$ ). About 76 percent of families in Pakistan are using flush toilet facilities which is the highest among all countries. Around 68 percent of families are using pit toilet facilities in Bangladesh. Reportedly, the highest percentage of families reported open defecation in India (44\%). Approximately 24 percent of families belong to poorest wealth quintile, followed by the poorer (21\%), Middle (20\%), Richer (19\%), and richest (16\%) respectively in pooled data of selected countries.

\subsection{Evolution of nutritional policies and anemia prevalence in selected South Asian countries}

Nutrition is currently relevant in South Asia's political agenda and most countries are implementing multi-sector national nutrition policies and plans to meet global nutrition targets. Here we describe the probable effect of historical nutrition policies and programs in four selected South Asian countries (Bangladesh, India, Nepal, and Pakistan) individually in light of anemia of children in the subsequent paragraphs.

Figure 1 shows the prevalence of anemia among children aged 0-59 months and the chronology of various efforts to improve India's nutritional status. Figure 1 shows a 77 percent prevalence of anemia among children aged 0-59 months in 1990. It also shows that 69 percent, 60 percent and 57 percent prevalence of anemia among children in 2000, 2010 and 2016 respectively. There is only 20 percentage points reduction took place in 26 years between 1990 and 2016 in India.

The high levels of maternal and child undernutrition in India have persisted despite strong constitutional Article 47-Duty of the State to improve nutrition and the standard of living and improve public health. Under this provision, the government started programs like Integrated Child Development Services (icds) in 1975, mid-day meal in 1984, nutrition policy in 1993, National Food Security Act 2013 mandating food and nutrition entitlements for children, pregnant and breastfeeding mothers with maternity support. The Infant Milk Substitutes, Feeding Bottles and Infant Foods Act 1992, and Amendment Act 2003 provides a robust policy framework for protecting, supporting and promoting nutrition interventions, especially during periods of greatest vulnerability for children and women.

Figure 2 shows the prevalence of anemia among children aged 0-59 months and the chronology of various efforts to improve Bangladesh's nutritional status. Figure 2 displays a 73 percent prevalence of anemia among children in 1990. It also shows that 62 percent 48 percent and 40 percent prevalence of anemia among children in 2000, 2010 and 2016 respectively. There is 33 percentage points reduction took place in 26 years between 1990 and 2016 in Bangladesh.

The 1972 constitution of Bangladesh was the first step towards a focused nutrition policy. The high levels of maternal undernutrition in Bangladesh have persisted, despite the vital constitutional provision within the 1972 constitution that declared the improvement of citizens' nutritional status as a primary responsibility of the State. Bangladesh constitution article 18-1 says that "the State shall regard raising the level of nutrition and improvement of public health as among its primary duties" (Shahan \& Jahan, 2017). Consequently, efforts were made to devise policies that would help the State to perform its responsibilities. In 1974, the Institute of Public Health Nutrition was set up to help the government formulate policy and strategy for nutrition-related activities and programmes. This was followed by the establishment of the Bangladesh National Nutrition Council (BNNC) in 1975 (Shahan \& Jahan, 2017 ) (Mannan, 2003), a National Food and Nutrition Policy in 1997 and a National Food Policy in 2006.

Figure 3 shows the prevalence of anemia among children aged 0-59 months and the chronology of various efforts to improve Nepal's nutritional status. Figure 3 manifests a 74 percent prevalence of anemia among children in 1990. It also shows that 64 percent 48 percent and 43 percent prevalence of anemia among children in 2000, 2010 and 2016 respectively. There is 31 percentage points reduction took place in 26 years between 1990 and 2016 in Nepal.

Nepal attempted multiple measures to address nutritional problems in the country. It is a fundamental human right enshrined in the 'Convention on the Rights of the Child (CRC) 1989. After the National Nutrition Strategy in 1978. Further, Nepal National Plan of Action for Nutrition 1998, Nepal Health Sector Programme- Implementation Plan 2004-2009, National Nutrition Policy and Strategy 2004, National Plan for Action on Nutrition (NPAN) 2007, National 
Nutrition Policy and Strategy 2008 and current National Nutrition Program(Pahari, 2011) were implemented. The government has also implemented the School Health and Nutrition Strategy 2006 to improve school-aged children's health and nutrition status. Despite these efforts, Nepal is among ten countries with the highest stunting prevalence, a measure of chronic under-nutrition, and one of the top twenty countries with the largest number of stunted children by UNICEF, 2009 (National Planning Commission, 2012).

Figure 4 shows the prevalence of anemia among children aged 0-59 months and the chronology of various efforts to improve Pakistan's nutritional status. Figure 4 manifests a 71 percent prevalence of anemia among children in 1990. It also shows that 59 percent 57 percent and 59 percent prevalence of anemia among children in 2000, 2010 and 2016 respectively. There is only 12 percentage points reduction took place in 26 years between 1990 and 2016 in Pakistan.

Historically, nutrition has been a low priority domain in Pakistan, with low political leadership visibility. However, Pakistan renewed its pledge to improve the population's health outcomes when it signed the World Health Organization's Alma-Ata Declaration in 1978, which laid the foundations for "Health for All" by 2000 (Turab, Tahir, \& Zaidi, 2018). As per Article 38, the right to food is enshrined in the constitution. Further, the National Program for Family Planning and Primary Health Care comes into the picture, commonly known as the Lady Health Worker Program, which was initiated under the construct of family planning within the National Health Policy of 1990. There was a high prevalence (71\%) of anemia among children in 1990. After reviewing the effect of the National Health Policy of 1990, the government made successive attempts to streamline it further in 1997 and 2001. The National Health Policy of 1997 emphasized the necessity for health promotion and health education initiatives. Despite these efforts, Pakistan did not achieve required level improvement. Further, the 2008 MDG Gap Task Force report revealed that Pakistan still lagged in several MDG indicators, with at least 24 indicators off track by the United Nations (UN) in 2008. These revelations forced policymakers

to draft the National Health Policy of 2009 to address domestic concerns and to strive to achieve the MDGs (GoP, 2009), (Turab, Tahir, \& Zaidi, 2018).

\section{Discussion}

Malnutrition alters bodily growth and evolution and is an underlying cause of increased morbidity and mortality in developing nations. Estimations show two billion people to be troubled worldwide due to malnutrition. Childhood mortality is resulting from different sorts of malnutrition amount to 2.6 billion suggesting an enormous global disease burden. Malnourishment is highly widespread among Asian children as Asia is estimated to accommodate $70 \%$ of the world malnourished children.

The south Asian countries are peculiar with their dietary practices and living style compared to the rest of the world. In this region, malnutrition's critical reasons were inadequate food supply, micronutrient deficiencies, low household income, illiteracy, unhygienic and substandard living, inappropriate child's care and caregiver, food insecurity and vicious cycle of poverty.

The causes of malnutrition are complex as a vicious cycle of poverty plays a significant role in the dominance of malnutrition in selected countries. Food insecurity largely troubles population groups of low socioeconomic status, and more impoverished families may not be able to have access to nutritious foods due to poverty. However, fundamental determinants for malnutrition may vary within different developing countries of South Asia. In light of Sustainable Development Goals (SDG), a multi-faceted policy should be implemented to prevent and control malnutrition problems in these countries. The policy should cover all aspects: dietary support, supporting exclusive breastfeeding and appropriate complementary feeding, providing micronutrient fortification and supplementation, improving education, providing nutritional awareness to adolescent girls and mothers, and completing immunizations coverage to prevent infectious disease, ensuring poverty alleviation and food security.

Since Article 47 of Indian constitution assigned a duty on the state to improve nutrition, standard of living and improve public health in 1950 , the Indian government started several programs like Mid-day meal programme in primary schools by Tamil Nadu govt in 1962, ICDS programme in 1975, Food for work programme in 1977, Nutritious food scheme to reduce malnurishment- Tamil Nadu in 1982, Mid-day meal by Kerala govt in 1984. After having constitutional right and several national and state level nutrition programs in 40 years between 1950 to 1990, 77 percent of Indian children aged 0-59 months were anaemic. This plight situation might be the outcome of three major reasons. Firstly, India's engagement in several wars (Kashmir War 1947-48; India-China war of 1962, India-Pakistan war of 1965); Closed economy and lastly India got independence in 1947 only. After ten years, India got eight percent reduction in anaemia from 1990 (77\%) to 2000 (69\%). In this duration, Indian govt made several programs like Mid-day meal extended to 12 states in 1991, Feeding Bottles and Infant Foods Act in 1992, Nutrition policy in 1993 and launched the Targeted Public Distribution System (TPDS) to resolve the problems of poor communities in 1997 etc. From 2001 (68\%) to 2010 (60\%), India again achieved eight percent reduction in anaemia of child that might be with the help of several policies like extended Mid Day Meal Scheme in 2002, National Health Policy in 2003, National Food for work (NFWP) in 2004, Adopted National Food Security Mission in 2007, National Rural Drinking Water Programme (NRDWP) in 2009 etc. India could not keep the reduction rate, after 2010, after making several policies like National Rural livelyhood Mission in 2011, National Policy for Children in 2013, National Food Security Act in 2013, Indira Gandhi Matritva Sahyog Yojana in 2014 etc. Therefore, from 2011 (59\%) to 2016 (57\%), India achieved only two percent reduction. The reason behind the low reduction might be the problem in connection with implementation of the programs.

Bangladesh became as an independent country from Pakistan in 1971 unlike India. Bangladesh also gives food right to its citizen by constitutional provisionarticle 18-1. Under this provision, Bangladesh had set up several institutions like institute of Public Health Nutrition to assist the government in formulating policy and strategy for nutrition related activities and programmes in 1975, Bangladesh National Nutrition Council (BNNC) in 1975. About 73 percent of Bangladesh children aged 0-59 months were anaemic in 1990 after 20 years of independence with constitutional food right and several efforts. After ten years, Bangladesh reduced 11 percent in anaemia from 1990 (73\%) to 2000 (62\%) by several efforts like nutrition Policy and Program for Bangladesh, which was approved by the BNNC and published, Conference on Nutrition in 1992, participated in World Food Summit in 1996, National Food and Nutrition policy in 1997 etc. From 2000 (62\%) to 2010 (48\%), Bangladesh again achieved 14 percent reduction in anaemia of child that might be with the help of effective 
policies like National Food Policy in 2006 and previous policies as well. Bangladesh kept the reduction rate even after 2010 and again reduced eight percent of anemia between 2010 (48\%) and $2016(40 \%)$.

Nepal attempted multiple measures to address nutritional problems in the country. It is a fundamental human right enshrined in the 'Convention on the Rights of the Child (CRC) 1989. After the National Nutrition Strategy in 1978. Further, Nepal National Plan of Action for Nutrition 1998, Nepal Health Sector Programme- Implementation Plan 2004-2009, National Nutrition Policy and Strategy 2004, National Plan for Action on Nutrition (NPAN) 2007, National Nutrition Policy and Strategy 2008 and current National Nutrition Program(Pahari, 2011) were implemented. The government has also implemented the School Health and Nutrition Strategy 2006 to improve school-aged children's health and nutrition status. By these efforts, Nepal has reduced its anemia by 31 percentage from 74 percent in 1990 to 43 percent in 2016.

Article 38 of the Pakistan constitution gives the right to food. After having constitutional right in 40 years between 1950 to 1990,70 percent of Pakistan children aged 0-59 months were anaemic. This plight situation might be the outcome of two major reasons. Firstly, Pakistan's engagement in big wars with India (Kashmir War 1947-48; India-Pakistan war of 1965); and Secondly Pakistan got independence in 1947 only. After ten years, Pakistan got 12 percent reduction in anaemia from 1990 (71\%) to 2000 (59\%). In this duration, Pakistan govt made several programs like National Health Policy in 1990, Launched the National Programme for Family Planning and Primary Healthcare in 1994, Streamline it further of National Health Policy in 1997, National Vitamin A strategy meeting was held in 1999 and these policies might have played an important role to get 12 percent anaemia reduction among children. From 2000 (59\%) to 2010 (57\%), Pakistan achieved only two percent reduction which clearly manifests the prelude of priority changes from child health. Pakistan's priority changes from child health have been crystal clear when its anaemia prevalence increase by two percent from 2010 (57\%) to 2016 (59\%).

In selected countries have a constitutional base to provide nutritional support to their citizens; thus, India, Pakistan, Bangladesh, and Nepal have implemented nutritional programs. The prevalence of anemia among children in 2016 shows that selected countries' efforts need to develop a comprehensive nutritional plan to deal with anemia. India and Pakistan have a 70-year history, whereas Nepal and Bangladesh have a more than 50-year history of implementation, but anemia's prevalence is still high. These findings suggest that there is scope for strategy improvement.

Figure 1 to 4 reveals that all the countries have high anemia among children in 1990. The prevalence of anemia started declining in South Asian countries. Despite progress in the last decade for anemia reduction in children, anemia continues to be a major public health concern in South Asia. Our findings have revealed to accelerate anemia reduction, a holistic approach targeting the known underlying determinants of anemia is needed.

The study finds nutritional programs have a positive impact on the prevalence of anemia. The high prevalence was observed in 1990 and started to decline over time. A similar declining trend was observed in all the selected countries, except Pakistan. The majority of anemia increases after 2010 in Pakistan, which shows a lack of interest in implementing the nutritional policy. On the other hand, the low prevalence was observed in Bangladesh and Nepal despite fewer policies and programs than in India and Pakistan which manifests quality of policy is more important rather than quantity of policy. The study suggests, to eradicate anemia among the children, India and Pakistan need to take a lesson from the neighboring countries.

\section{Conclusions}

To conclude, the problem of under-nutrition in Pakistan and India stems from lack of serious implementation of their National Nutrition Policies. Reduction in anemia among children requires strong political will to implement policies and programs.

The silent under-nutrition crisis in Pakistan and India is quite alarming, particularly regarding children (the future of the society), and Government response is urgently required. The National Nutrition Policies must be revisited and modernized and should address the problem holistically in reference with the latest demographic and epidemiological data. What all selected countries urgently need is the political will to address anemia by effective programs and satisfactory financial allocations that address the structural and systemic causes of anemia. Policies should have monitorable targets, real-time monitoring and evaluation mechanisms, and accountability systems. In light of Sustainable Development Goals (SDG), a multi-faceted policy should be implemented to prevent and control malnutrition problems in these countries. Lastly, as we know that ministries work vertically (individually) in most of the countries but we must understand that drafting and implementing the National Nutrition Program would require coordination between major ministries within a country to get required level success. Undoubtedly, single ministry cannot grip this extremely multi-sectoral subject.

\section{Limitations Of The Study}

The study provides a comparative understanding between nutrition policies and nutritional status of under-five children in four South Asian countries namely Bangladesh, India, Nepal, and Pakistan. Although, the reduction of anemia is the outcome of many efforts but this study assumed that the introduction of exclusive nutrition policies and programmes by stated four South Asian countries played an important role in anemia reduction among under-five children since exclusive nutrition policies are meant to improve nutritional situation.

\section{Declarations}

\section{Ethics approval and consent to participate}

Not applicable

\section{Consent for publication}


Not applicable

\section{Availability of data and materials}

Data has been taken from the Global Health Observatory Data Repository (GHODR), Demographic Health Survey (DHS) and reviews some of the critical interventions in nutrition within the different countries and draws out several issues that bear on these policies' future evolution which are publicly available.

\section{Conflict of Interest}

No conflict of interest was reported by all authors.

\section{Funding}

This research received no specific grant from any funding agency in the public, commercial, or not-for-profit sectors.

\section{Authors' contributions}

Both authors contributed significantly for this manuscript.

\section{Acknowledgements}

This study would not have been possible without the enthusiastic cooperation as well as the advice of our respected professor R.B. Bhagat.

\section{References}

1. Amuna P, Zotor FB. (2008). Epidemiological and nutrition transition in developing countries: Impact on human health and development. Proceedings of the Nutrition Society, 67(1), 82-90. https://doi.org/10.1017/S0029665108006058.

2. Bharati S, Pal M, Chakrabarty S, Bharati P. Socioeconomic determinants of iron-deficiency anemia among children aged 6 to 59 months in India. Asia Pacific Journal of Public Health. 2015;27(2):NP1432-43.

3. Bishai D, Nalubola R. The history of food fortification in the United States: Its relevance for current fortification efforts in developing countries. Econ Dev Cult Change. 2002;51(1):37-53. https://doi.org/10.1086/345361

4. Black RE, Victora CG, Walker SP, Bhutta ZA, Christian P, De Onis M, Ezzati M, Grantham-Mcgregor S, Katz J, Martorell R, Uauy R. Maternal and child undernutrition and overweight in low-income and middle-income countries. In The Lancet (Vol. Elsevier BV. 2013;382:Issue 9890, pp. 427-51. https://doi.org/10.1016/S0140-6736(13)60937-X.

5. Chowdhury MRK, Khan MMH, Khan HT, Rahman MS, Islam MR, Islam MM, Billah B. Prevalence and risk factors of childhood anemia in Nepal: A multilevel analysis. Plos one. 2020;15(10):e0239409.

6. Demment MW, Young MM, Sensenig RL. (2003). Providing Micronutrients through Food-Based Solutions: A Key to Human and National Development. Journal of Nutrition, 133(11 SUPPL. 2), 3879S-3885S. https://doi.org/10.1093/jn/133.11.3879s.

7. Darnton-Hill I, Nishida C, James WPT. A life course approach to diet, nutrition and the prevention of chronic diseases. Public Health Nutr. 2004;7(1a):10121.

8. Gebreweld A, Ali N, Ali R, Fisha T. Prevalence of anemia and its associated factors among children under five years of age attending at Guguftu health center, South Wollo, Northeast Ethiopia. PloS one. 2019;14(7):e0218961.

9. Hoffman D, Cacciola T, Barrios P, Simon J. Temporal changes and determinants of childhood nutritional status in Kenya and Zambia. Journal of Health Population Nutrition. 2017;36(1):27. https://doi.org/10.1186/s41043-017-0095-z.

10. Hunt JM, John P. (2005). The potential impact of reducing global malnutrition on poverty reduction and economic development. In Asia Pac J Clin Nutr (Vol. 14).

11. Keokenchanh S, Kounnavong S, Midorikawa K, Ikeda W, Morita A, Kitajima T, Sokejima S. Prevalence of anemia and its associated factors among children aged 6-59 months in the Lao People's Democratic Republic: A multilevel analysis. Plos one. 2021;16(3):e0248969.

12. Khan JR, Awan N, Misu F. Determinants of anemia among 6-59 months aged children in Bangladesh: evidence from nationally representative data. BMC Pediatr. 2016;16(1):1-12.

13. Kismul H, Acharya P, Mapatano MA, Hatløy A. (2017). Determinants of childhood stunting in the Democratic Republic of Congo: Further analysis of Demographic and Health Survey 2013-14. In BMC Public Health (Vol. 18, Issue 1, pp. 1-14). BioMed Central Ltd. https://doi.org/10.1186/s12889-0174621-0.

14. Singh RK, Patra S. (2014). Extent of anaemia among preschool children in EAG States, India: a challenge to policy makers. Anemia, 2014.

15. Sulaiman A, Bushara S, Elmadhoun W, Noor S, Abdelkarim M, Aldeen I, Osman M, Almobarak A, Awadalla H, Ahmed M. Prevalence and determinants of undernutrition among children under 5-year-old in rural areas: A cross-sectional survey in North Sudan. Journal of Family Medicine Primary Care. 2018;7(1):104. https://doi.org/10.4103/jfmpc.jfmpc_73_17. 
16. Tasnim T. (2018). Determinants of Malnutrition in Children Under Five Years in Developing Countries: A Systematic Review. Indian Journal of Public Health Research \& Development. https://web.b.ebscohost.com/abstract?

direct=true\&profile=ehost\&scope=site\&authtype=crawler\&jrnl=09760245\&AN=130757212\&h=yWN3azyjADXsBofGwwTY8cBIS9knPxK8VQAhpxCXOvS58C

17. Unicef. (2018). 2018 Global Nutrition Report reveals malnutrition is unacceptably high and affects every country in the world. https://www.unicef.org/rosa/press-releases/2018-global-nutrition-report-reveals-malnutrition-unacceptably-high-and-affects.

18. Villalpando S, Shamah-Levy T, Ramírez-Silva Cl, Mejía-Rodríguez F, Rivera JA. Prevalence of anemia in children 1 to 12 years of age: results from a nationwide probabilistic survey in Mexico. Salud pública de México. 2003;45:490-8.

19. Wagnew F, Tesgera D, Mekonnen M, Abajobir AA. Predictors of mortality among under-five children with severe acute malnutrition, northwest ethiopia: An institution based retrospective cohort study. Archives of Public Health. 2018;76(1):1-10. https://doi.org/10.1186/s13690-018-0309-x.

20. WHO. (2021). World health organization. Retrieved from: https://www.who.int/news-room/fact-sheets/detail/malnutrition.

21. Yusuf A, Mamun ASMA, Kamruzzaman M, Saw A, El-Fetoh NMA, Lestrel PE, Hossain MG. Factors influencing childhood anaemia in Bangladesh: a two level logistic regression analysis. BMC Pediatr. 2019;19(1):1-9.

\section{Figures}

Figure 1: Prevalence of anemia among children aged 0-59 months and the chronology of various efforts to improve their nutritional status, India: 1950-2016

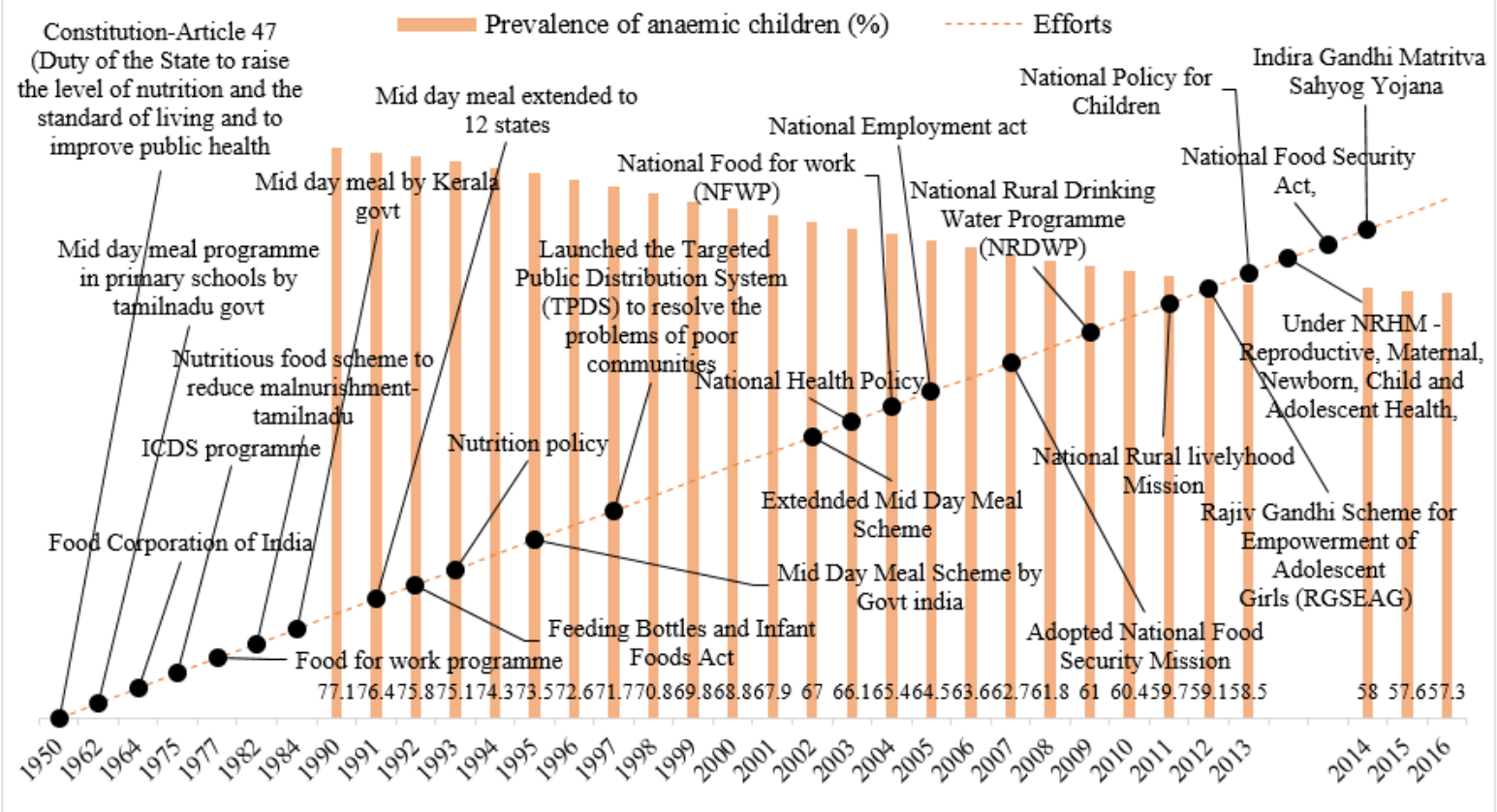

Source: World Health Organization, Global Health Observatory Data Repository/World Health Statistics ( apps.who.int/gho/data/node.main.1?lang=en ).(27/09/2020, 11.am)

Figure 1

Please See image above for figure legend. 
Figure 2: Prevalence of anemia among children aged 0-59 months and the chronology of various efforts to improve their nutritional status, Bangladesh: 19712016

Prevalence of anaemic children (\%) Efforts

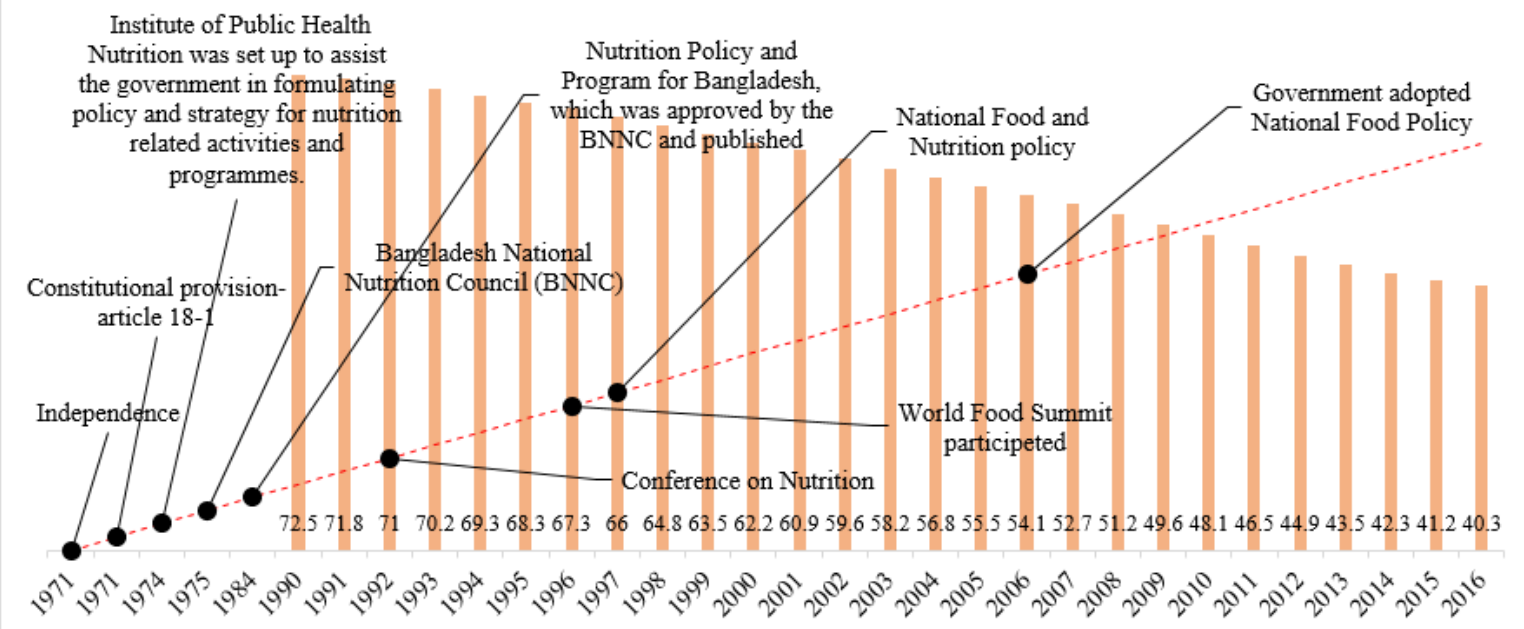

Source: World Health Organization, Global Health Observatory Data Repository/World Health Statistics ( apps.who.int/gho/data/node.main.1?lang=en ).(27/09/2020, 11.am)

Figure 2

Please See image above for figure legend.

Figure 3: Prevalence of anemia among children aged 0-59 months and the chronology of various efforts to improve their nutritional status Nepal: 1978-2016

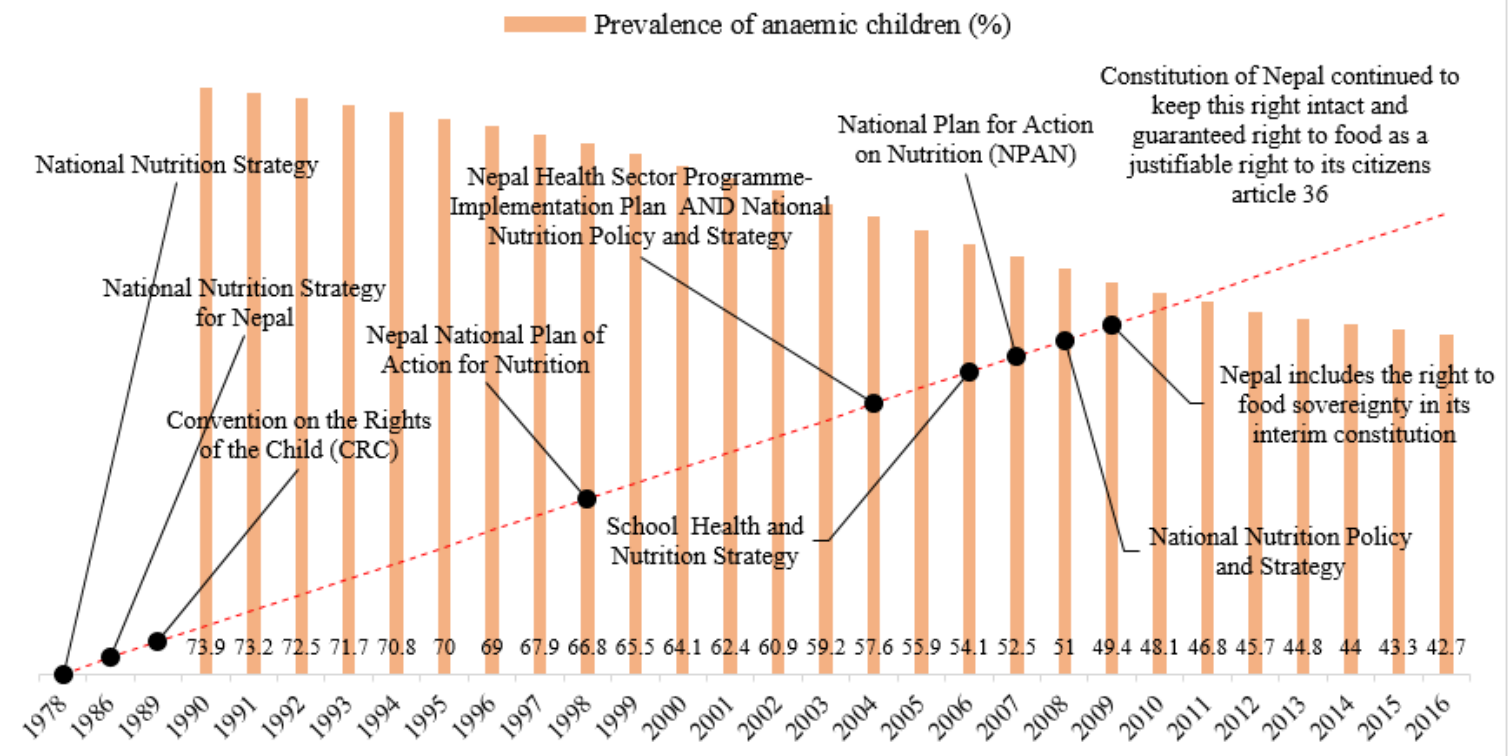

Source: World Health Organization, Global Health Observatory Data Repository/World Health Statistics ( apps.who.int/gho/data/node.main.1?lang=en ).(27/09/2020, 11.am)

\section{Figure 3}

Please See image above for figure legend. 
Figure 4: Prevalence of anemia among children aged 0-59 months and the chronology of various efforts to improve their nutritional status, Pakistan: 1950-

2016

Prevalence of anaemic children (\%) _....- Efforts

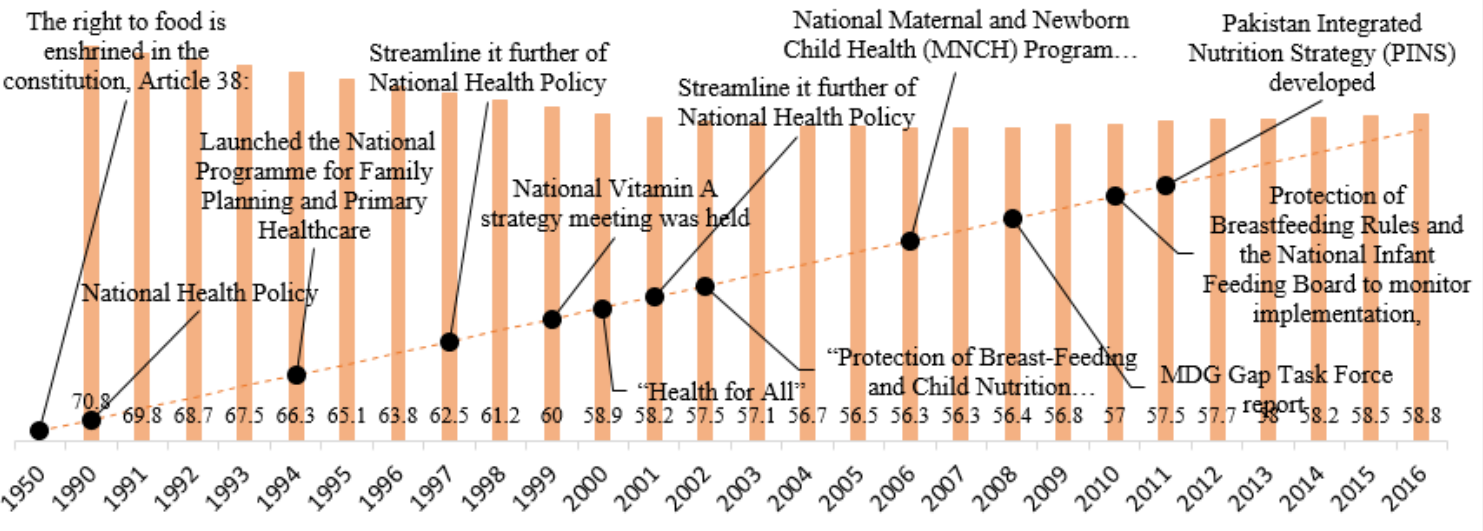

Source: World Health Organization, Global Health Observatory Data Repository/World Health Statistics ( apps.who.int/gho/data/node.main.1 ?lang=en ).(27/09/2020, 11.am)

Figure 4

Please See image above for figure legend.

Figure 5: Lifecourse approach: the proposed causal links

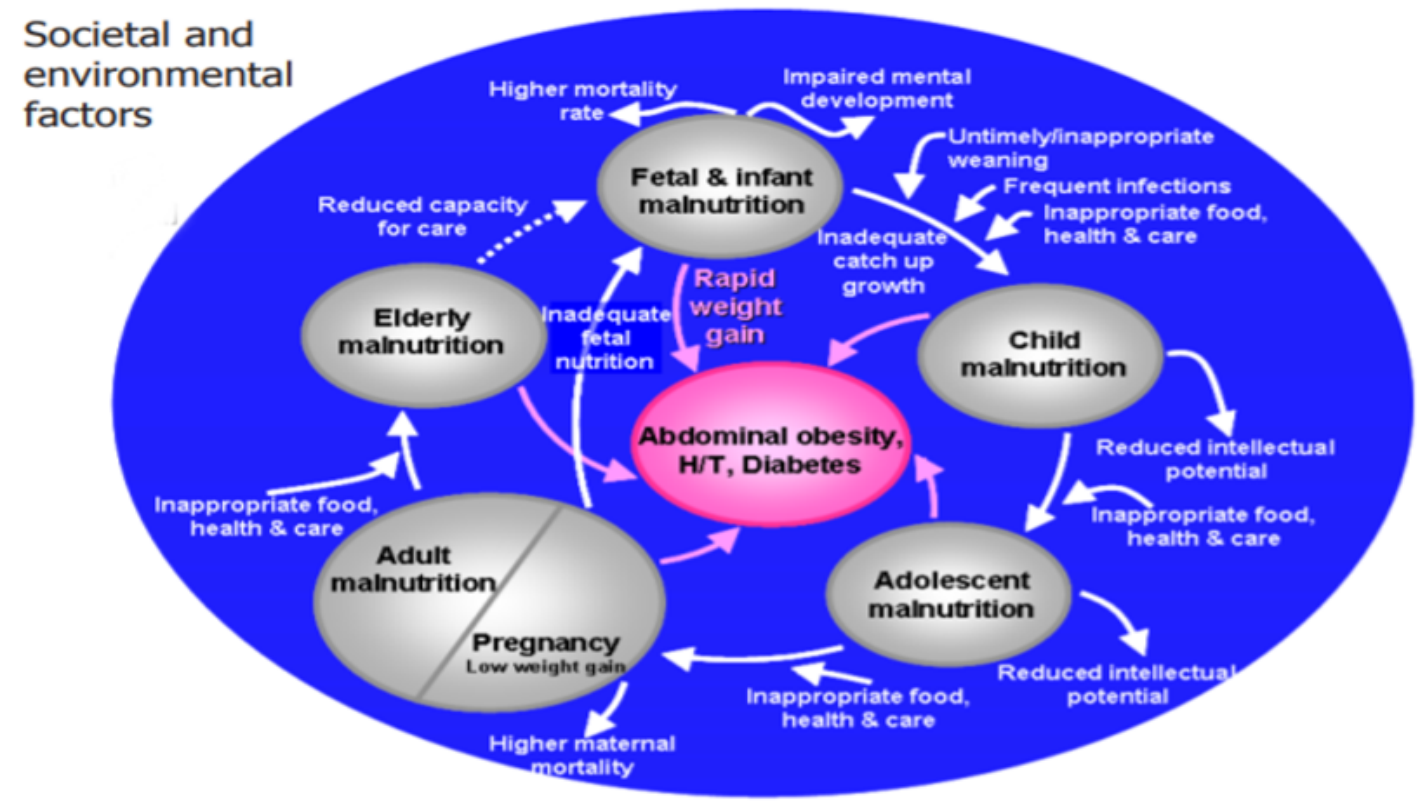

Source: (Darnton-Hill et al., 2004)

Figure 5

Please See image above for figure legend. 